cal methods for acid mucopolysaccharides, such as colloidal iron and Alcian blue. MassonFontana stain for melanin pigment may also occasionally prove positive in a few balloon cells. Other differential diagnoses should include, in the ocular context, sebaceous adenoma, granular cell tumour, clear cell hydradenoma, and malignant clear cell neoplasms. In granular cell tumour, the cytoplasm can also look clear although at high power it is usually finely granular. Features more in keeping with a diagnosis of balloon cell naevus in this case are the absence of immunoreactivity to panmacrophage markers (granular cell tumour are often positive) and the presence of characteristic naevus cells adjacent to the main lesion. Adnexal tumours could be ruled in or out of the diagnosis on the basis of cytokeratin staining.

IRENE PECORELLA

ANTONIO CIARDI
Dipartimento di Medicina Sperimentale e Patologia, Università degli Studi di Roma 'La Sapienza', Rome, Italy

SANTI MARIA RECUPERO

II Cinica Oculistica, Università degli Studi di Roma

'La Sapienza', Rome, Italy

Correspondence to: Dr Irene Pecorella, Dipartimento di Medicina Sperimentale e Patologia, Policlinico Universitario 'Umberto I', Università degli Studi 'La Sapienza', V le Regina Elena, 324-00161 Rome, Italy.

Accepted for publication 13 September 1996

1 Naumann G, Yanoff $M$, Zimmerman LE. Histogenesis of malignant melanomas of the uvea: I Histopathologic characteristics of nevi of the choroid and ciliary body. Arch Ophthalmol the choroid and

2 Riley FC. Balloon cell melanoma of the choroid. Arch Ophthalmol 1974;92:131-3.

3 Folberg R, Jakobiec FA, Bernardino VB, Iwamoto T. Benign conjunctival melanocytic lesions. Clinicopathological features. Ophthalmology 1989;96:436-61.

4 Pfaffenbach DD, Green WR, Maumenee AE. Balloon cell nevus of the conjunctiva. Arch Ophthalmol 1972;87:192-5.

\section{Bone formation in rejected corneal graft}

EDITOR,-Intraocular bone formation is a well known phenomenon that occurs mainly in long standing phthisical eyeballs. ${ }^{1}$ Presence of bone was reported also in cases of epibulbar osseous choristoma ${ }^{2}$ as well as in scleras of a patient with chronic renal failure. ${ }^{3}$ We present, to our knowledge for the first time, bone formation in the cornea.

\section{CASE REPORT}

A 47-year-old woman, known to suffer from congenital glaucoma, had bilateral completely opaque large corneas. She had been treated in another hospital at the age of 15 years, undergoing corneal graft in her left eye, but the graft opacified soon after surgery.

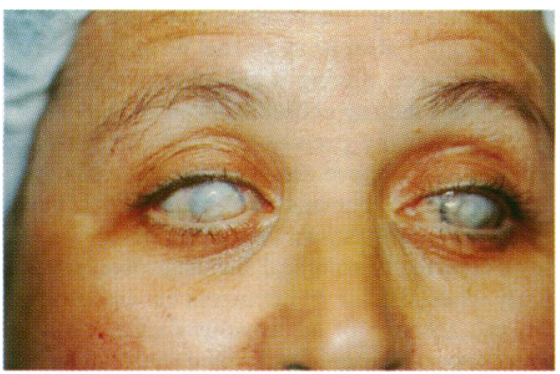

Figure 1 Clinical picture showing the completely opaque and vascularised right cornea, and the opaque corneal graft in the left eye.

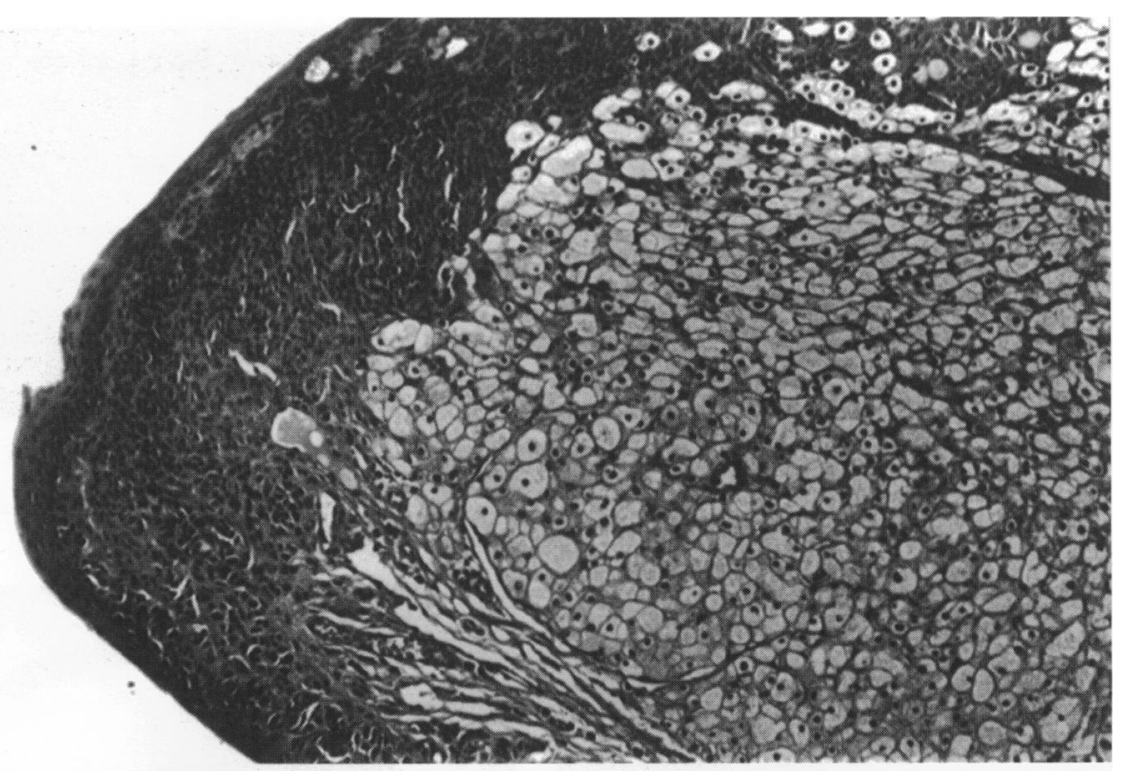

Figure 1 Caruncular compound naevus, predominantly composed of large, clear cells. Towards the surface, small melanocytes with the formation of few nests can be recognised. Haematoxylin and eosin, $\times 250$.
In her first visit in our eye clinic her visual acuity was no light perception in the right eye and light perception in the left eye. Both corneas were completely opaque and vascularised (Fig 1), and the retrocorneal parts of the eyes could not be examined. Ultrasound examination of the left eye revealed an axial length of $31 \mathrm{~mm}$ and dislocated lens in the vitreous. Because of the potential for vision in the left eye, perforating keratoplasty was performed under local anaesthesia; the recipient corneal button was sent for histopathological evaluation. Four months after surgery the corrected visual acuity of the operated eye was finger counting from 1 metre. The cornea was clear, enabling visualisation of the fundus that showed almost total cupping of the optic nerve head. The patient has been treated by antiglaucomatous drugs and topical and systemic corticosteroids.

The specimen that was submitted to our ophthalmic pathology laboratory consisted of a completely opaque and thickened corneal button measuring $7 \mathrm{~mm}$ in diameter. In cutting the cornea with the microtome, it was found to be hard; therefore, we performed decalcification. Microscopic examination revealed scarred, vascularised, and inflamed corneal tissue with irregular epithelium and almost no Bowman's layer. Areas of calcification were seen in the superficial corneal layers, some in the form of band keratopathy and others as large calcified stromal areas. A large piece of bone formation with fibrovascular bone marrow was located in the deeper stromal layers (Fig 2). Another small piece of bone was seen more superficially. The Descemet's membrane was broken and folded, and thick fibrous tissue was seen behind it. Some melanin pigmentations (Fontana staining positive; PERLS staining negative) were found in the posterior stromal layers.

\section{COMMENT}

In a large series ${ }^{1}$ of 2486 enuculated eyes, $4.8 \%$ had intraocular ossification. In $69 \%$ of them marrow was found within the hetero-
Figure 2 Histological section of the cornea showing superficial vascularisation and calcifications, and two layers of bone tissue with bone marrow in the deep stromal layers (haematoxylin and eosin, $\times 40)$. 
topic bone. The most frequent site was in the region of the retinal pigment epithelium and the inner surface of the choroid, mainly in the posterior pole. Other sites of ossification were the lens, retina, vitreous, and cyclitic membranes. Lens ossification was also reported by others as solitary findings. ${ }^{4}$ Corneal ossification has not been reported previously.

Most eyes with intraocular bone formation were severely injured or inflamed, usually years before enucleation of the eye. Some authors have raised the hypothesis that adequate blood supply and fibroblastic response appear necessary for ossification. It should be mentioned that metaplasia of fibrous connective tissue to bone may occur in old scars in many sites in the body. Another fact is that intraocular bone formation occurs more in the vicinity of pigmented tissue, such as retinal pigment epithelium, that is known to undergo fibroblastic metaplasia and ossification, as well as in the vicinity of the choroid. ${ }^{1}$ The cornea in our case was removed from an eye with long standing disease that underwent surgical trauma and had vascularisation and pigmentation in the stroma. All these factors may have contributed to bone formation in the cornea of the present case.

JACOB PE'ER SHMUEL LEVINGER

Department of Ophthalmology, Hadassah University Hospital, Ferusalem, Israel
Correspondence to: Jacob Pe'er, MD, Department of Ophthalmology, Hadassah University Hospital, PO Box 12000, Jerusalem 91120, Israel.

Accepted for publication 12 September 1996

1 Finkelstein EM, Boniuk M. Intraocular ossification and hematopoiesis. Am $\mathcal{f}$ Ophthalmol 1969;68:683-90.

2 Mansour AM, Barber JC, Reinecke RD, Wang FM. Ocular choristomas. Surv Ophthalmol 1989;33:339-58.

3 Spencer WH, ed. Ophthalmic pathology: an atlas and textbook. 3rd ed. Philadelphia: WB Saunders, 1985:389-422.

4 Samuels B. Cataract complicating corneal scars after perforating ulcers. Arch Ophthalmol 1943; 23:583-99. 